EarthArXiv coversheet for:

Remote bed-level change and overwash observation with low-cost ultrasonic distance sensors

Ian R.B. Reeves, ${ }^{1 *}$ Evan B. Goldstein, ${ }^{2}$ Katherine A. Anarde, ${ }^{1}$ and Laura J. Moore ${ }^{1}$

1) Department of Geological Sciences, University of North Carolina at Chapel Hill, 104 South Road, Chapel Hill, NC 27599, USA

2) Department of Geography, Environment, and Sustainability, University of North Carolina at Greensboro, 1009 Spring Garden Street, Greensboro, NC 27412, USA

${ }^{*}$ Corresponding author: reevesi@live.unc.edu

This article has been peer-reviewed, and is a postprint from Shore \& Beach, published by ASBPA. Shore \& Beach authors retain copyright over their work, and the journal also permits the distribution of typeset manuscripts.

Citation of this article should use the following:

Reeves, I. R. B., Goldstein, E. B., Anarde, K. A., \& Moore, L. J. (2021). Remote bed-level change and overwash observation with low-cost ultrasonic distance sensors. Shore \& Beach, 89(2), 23-30. https://doi.org/10.34237/1008923 


\title{
Remote bed-level change and overwash observation with low-cost ultrasonic distance sensors
}

\author{
By
}

\author{
Ian R.B. Reeves, ${ }^{1 *}$ Evan B. Goldstein, ${ }^{2}$ Katherine A. Anarde, ${ }^{1}$ and Laura J. Moore ${ }^{1}$ \\ 1) Department of Geological Sciences, University of North Carolina at Chapel Hill, 104 South Road, Chapel Hill, NC 27599, USA \\ 2) Department of Geography, Environment, and Sustainability, University of North Carolina at Greensboro, \\ 1009 Spring Garden Street, Greensboro, NC 27412, USA \\ *Corresponding author: reevesi@live.unc.edu
}

\begin{abstract}
Few datasets exist of high-frequency, in situ measurements of storm overwash, an essential mechanism for the subaerial maintenance of barrier islands and spits. Here we describe a new sensor platform for measuring bed-level change and estimating overwash inundation depths. Our $\mathrm{MeOw}$ (Measuring Overwash) stations consist of two ultrasonic distance sensors, a microprocessor board, and a camera and are capable of withstanding the impacts of large storm events, can be left unattended to collect data for months to years, and are relatively inexpensive. With the exception of the camera, the $\mathrm{MeOw}$ stations are built with all open-source hardware and software. Herein we provide complete instructions for manufacturing the $\mathrm{MeOw}$ stations and present observations from a single $\mathrm{MeOw}$ station for a three-month (2019) deployment on a frequently overwashed section of Smith Island, VA. The MeOw stations captured three large storm events over the course of the deployment (Hurricane Dorian, Tropical Storm Melissa, and a November nor'easter), as well as several high-tide events. Based on our interpretation of the raw data, bed-level changes occurred throughout the deployment from both storm and non-storm overwash, but were particularly large during Tropical Storm Melissa where initial accretion of approximately $0.15 \mathrm{~m}$ was followed by $0.77 \mathrm{~m}$ of erosion over three days. The maximum overwash inundation depth occurred during the noreaster and measured approximately $0.83 \mathrm{~m}$. The variability in bed level over the course of our experiment highlights the importance of in situ high frequency bed-level measurements for constraining overwash inundation depths. MeOw stations are ideally suited for measuring storm overwash - or any process that necessitates tracking bed and water level elevations at high frequency during harsh conditions.
\end{abstract}

$\mathrm{O}$ verwash, the landward flow of water and sediment over a dune (or berm) crest during highwater events, is an important process on sandy coastlines, and an essential mechanism for the subaerial maintenance of low-lying barrier systems. Barrier islands and spits maintain their elevation relative to sea level by migrating upward and landward primarily through the process of overwash, where sediment eroded from the front of a barrier (shoreface and beach) is transported to the top and back of the barrier (interior and backbarrier bay) (e.g. Dolan and Godfrey 1973; Donnelly et al. 2006). Overwash is also an important source of sediment for fringing back-barrier marshes, allowing overwash-fed marshes to persist under conditions in which they would otherwise disappear (Walters et al. 2014). On developed barrier islands, overwash can damage buildings and blanket roadways, resulting in significant cleanup expenses and blocking key transportation routes (e.g. Nordstrom 1994; Nelson and LeClair 2006; Rogers et al. 2015; Lazarus et al. 2021).

Overwash can be split into two regimes: run-up overwash occurs when wave run-up overtops the dune crest intermittently, whereas inundation overwash occurs when the water level is sufficiently high to continuously submerge the dune crest (Sallenger 2000). Along low-lying coastal systems, run-up and inundation overwash typically occur during storms but can also occur during non-storm conditions, for example due to extreme tides (Matias and Masselink 2017). Overwash processes are difficult to measure, owing to the inherent danger,
KEYWORDS: Overwash, sonar, erosion, hurricanes.

Manuscript submitted 15 February 2021; revised \& accepted 13 April 2021.

high energy, and unpredictability of high water-level events, especially when stormgenerated. As such, there is a dearth of in situ measurements of overwash processes, especially for overwash-driven bed elevation change. Flow and bed-level measurements are particularly useful for the parameterization of coastal numerical models, including event-scale models (e.g. Larson et al. 2004; Roelvink et al. 2009; Cohn et al. 2019), and potentially longer timescale models (e.g. LorenzoTrueba and Ashton 2014; Moore et al. 2010).

Previous attempts to measure overwash processes have used a variety of methods. Fisher et al. (1974) measured overwash throat velocities using current meters and collected suspended sediment samples by hand. Leatherman and Zaremba (1987) also measured throat velocities with current meters, whereas Bray and Carter (1992) timed the passage of wooden floats between markers to measure surface velocities of overwash sheet and channel flows. Holland et al. (1991) computed celerity vectors of overwash bores by analyzing video using large-scale particle image velocimetry, and calculated overwash depths using a cross-shore array of capacitance-style wave staffs. More recently, arrays of pressure transducers (Baldock et al. 2008; Hoekstra et al. 2009; Matias et al. 2010; Sherwood et al. 2014; VanDusen et al. 2016; Coogan et al. 2019; Lashley et al. 2019; Anarde et al. 2020) and current meters or velocimeters (Englestad et al. 2017; Matias et al. 2017, 2019) have been used to measure overwash depths and 


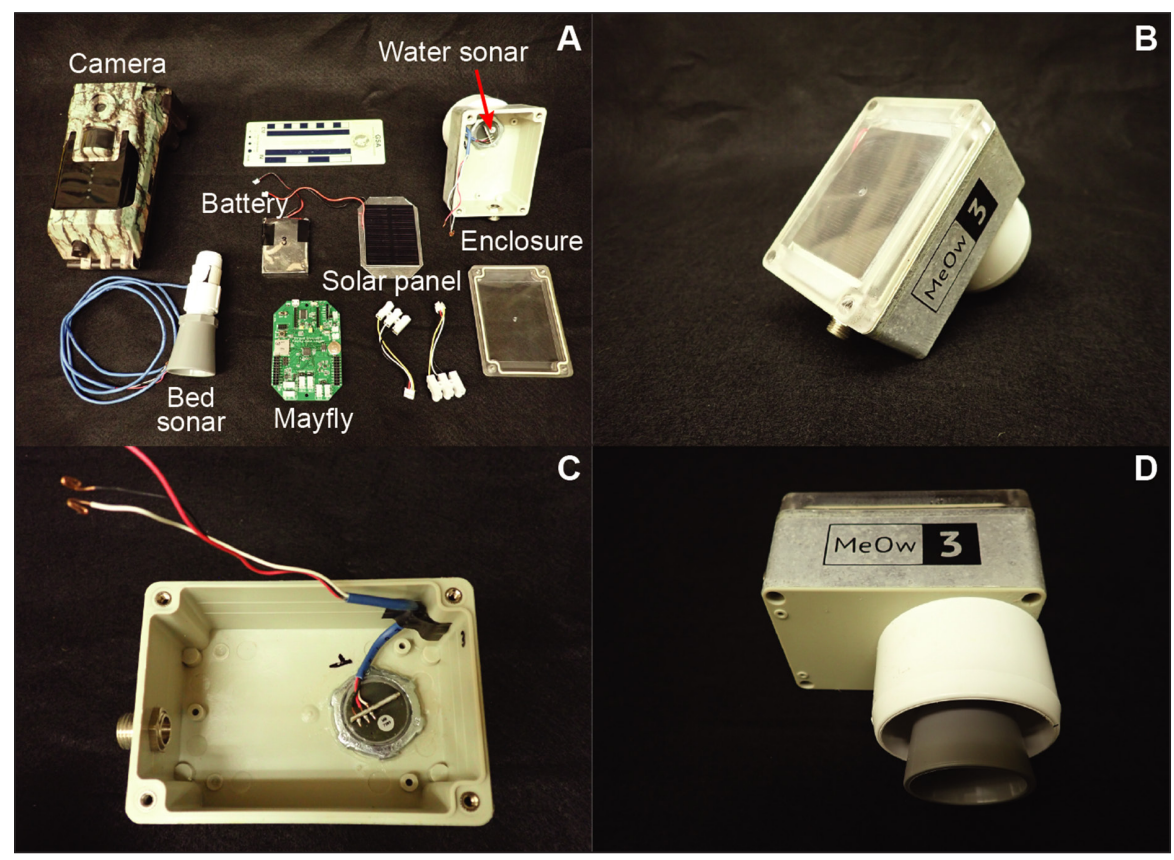

Figure 1. Images of (A) all MeOw hardware components, $(B)$ the enclosure and internal solar panel, $(C)$ the mounting of the water sonar through a hole in the bottom of the enclosure, and (D) the PVC cap attached to the underside of the enclosure.

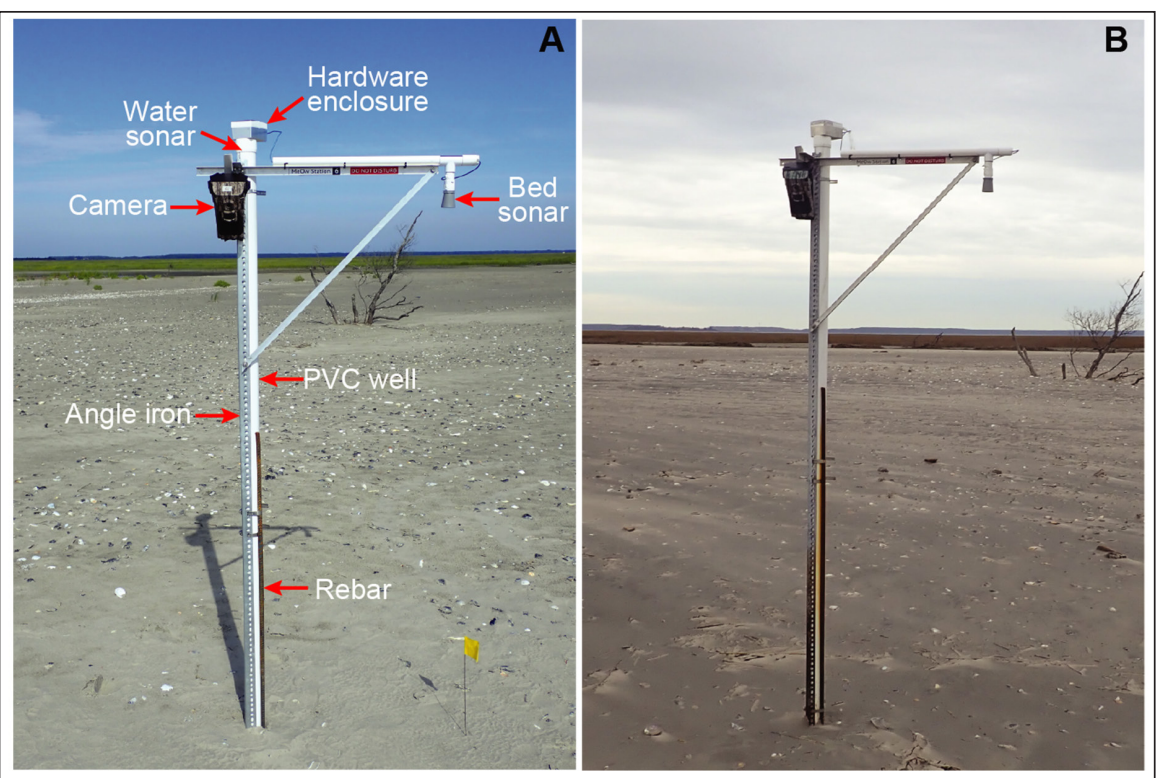

Figure 2. Images from (A) field installation of fully constructed MeOw station in the backshore (landward of the berm crest) on Smith Island, VA, with labeled components (taken 21 August 2019), and (B) the MeOw station upon instrument retrieval (taken 22 November 2019). Both photos are looking northwest.

hydrodynamics. Matias et al. (2010) also used fluorescent tracers to track sediment pathways and plugs of contrasting sand to calculate mixing depths. Importantly, each of these techniques is limited in one or more of the following ways, as they 1 ) require either in-person monitoring or frequent revisits (e.g. to download data or replace batteries); 2) are unsuitable for energetic storm events and/or long experiment durations; 3 ) do not track the an arm extending outwards from the well - to track water and sediment surface elevations at high frequency (once per minute) with very low battery consumption and storage capacity requirements. Sonar sensors have been shown to be useful for measuring bed levels (e.g. Houser 2012; Borrell and Puleo 2019). The MeOw stations are weather resistant and, if securely mounted, can withstand high wind, energetic waves, sediment deposition and/ or erosion, and be left unattended for months to potentially years. Additionally, their ability to track the bed elevation at high frequency immediately before and after overwash events reduces uncertainty in water depth measurements, which is, for example, an important factor for calculating wave energy flux during overwash (e.g. Anarde et al. 2020). We build the MeOw stations with open-source hardware and software, which has the benefit of allowing researchers to easily develop and modify equipment and code for their specific research needs and at a cost significantly lower than off-the-shelf products. Open hardware and software has the ability to further democratize data collection, and also allow for researchers to build bespoke equipment (e.g. Cressey 2017; Pearce 2012). We include the complete bill of materials, instructions, and a description of the software within this manuscript; code and wiring instructions are available online (Reeves 2021). In the following, we describe the development and construction of the $\mathrm{MeOw}$ stations, present data from extensive field testing, and discuss the limitations and considerations of this methodology.

\section{MATERIALS AND METHODS}

The MeOw stations consist of two ultrasonic distance sensors, a cellular trail camera, and a data logger, all mounted to a PVC and metal structure. One sonar sits inside a partially buried stilling well to measure continuous water levels, from groundwater to (mean) surface water; the other is attached to an arm extending outwards from the well to measure the bed elevation (when the surface is dry) or the water surface elevation (when the surface is inundated). For simplicity, we refer to the sonar inside the well as the water sensor, and the sonar outside the well as the bed sensor, though it is important to note that the bed sensor is actually measuring the water surface whenever the bed surface is submerged during a high-water event. The camera is used to 
Table 1.

Materials and price list for the construction of one MeOw station.

\begin{tabular}{|c|c|c|c|c|}
\hline Material/product & Manufacturer & Quantity & $\begin{array}{l}\text { Unit price } \\
\text { (USD) }\end{array}$ & $\begin{array}{l}\text { Total price } \\
\text { (USD) }\end{array}$ \\
\hline HRXL-MaxSonar-WRMT (MB7389-120) & Maxbotix & 2 & $\$ 149.95$ & $\$ 299.90$ \\
\hline Mayfly Data Logger & EnviroDIY & 1 & $\$ 60.00$ & $\$ 60.00$ \\
\hline Impulse Cellular Trail Camera & Bushnell & 1 & $\$ 299.99$ & $\$ 299.99$ \\
\hline ABS Enclosure (RP1095C) & $\begin{array}{l}\text { Hammond } \\
\text { Manufacturing }\end{array}$ & 1 & $\$ 10.49$ & $\$ 10.49$ \\
\hline 2500 mAh lithium polymer battery $(2 \times 2.55 \times 0.3$ in $)$ & Adafruit & 1 & $\$ 18.50$ & $\$ 18.50$ \\
\hline 0.5 watt solar panel $(55 \times 70 \mathrm{~mm})$ & Seeed Studio & 1 & $\$ 1.95$ & $\$ 1.95$ \\
\hline Grove universal 4-pin buckled $30 \mathrm{~cm}$ cables (5 pack) & Seeed Studio & 1 & $\$ 2.90$ & $\$ 2.90$ \\
\hline $\begin{array}{l}\text { PG7 stainless steel cable glands }(3-6 \mathrm{~mm} \text { diameter } \\
\text { cables) }-3 \text { pack }\end{array}$ & Various & 1 & $\$ 6.00^{*}$ & $\$ 6.00^{*}$ \\
\hline 3-conductor solid copper wire (22 gauge, 25 ft) & Various & 1 & $\$ 10.00 *$ & $\$ 10.00 *$ \\
\hline External PVC flat cap (2 in diameter) & FORMUFIT & 1 & $\$ 2.20$ & $\$ 2.20$ \\
\hline Internal PVC dome cap (2 in diameter) & FORMUFIT & 1 & $\$ 1.89$ & $\$ 1.89$ \\
\hline Schedule 40 PVC pipe (2 in diameter, 120 in length) & Various & 1 & $\$ 9.15^{*}$ & $\$ 9.15^{*}$ \\
\hline Schedule 40 PVC pipe (1 in diameter, 120 in length) & Various & 1 & $\$ 4.40^{*}$ & $\$ 4.40$ \\
\hline Schedule 40 PVC saddle snap tee $(1 \times 1 \times 3 / 4$ in threaded $)$ & Various & 1 & $\$ 1.90$ & $\$ 1.98$ \\
\hline Slotted angle iron (1.5 in width, 96 in length, 14 gauge) & Various & 1 & $\$ 35.50 *$ & $\$ 35.50^{*}$ \\
\hline Aluminum angle ( 1 in width, 96 in length, $1 / 16$ in thick) & Various & 2 & $\$ 11.75^{*}$ & $\$ 23.50$ \\
\hline Fastening hardware & Various & & $\$ 15.00^{*}$ & $\$ 15.00$ \\
\hline Rebar (0.5 in diameter, 120 in length) & Various & 1 & $\$ 6.25^{*}$ & $\$ 6.25$ \\
\hline 3-5 in stainless steel hose clamp & Various & 5 & $\$ 2.00^{*}$ & $\$ 10.00$ \\
\hline $\begin{array}{l}\text { Total } \\
\text { * Price approximations depending on brand location and time of purchase }\end{array}$ & & & & $\$ 819.60$ \\
\hline
\end{tabular}

remotely capture video and still images to ground-truth the sonar measurements. This section describes construction and testing of the MeOw stations. At time of publication, the total cost to construct a single station as described herein is approximately $\$ 820$ USD. This compares favorably to, for example, commercial pressure transducers, which can cost anywhere from several hundreds to thousands of dollars for a single logger (and without an additional camera). The complete bill of materials is given in Table 1 , and the wiring instructions, sensor code, and processing/plotting code are available online (Reeves 2021).

\section{Hardware}

Each MeOw station uses two HRXLMaxSonar-WRMT (MB7389-120) ultrasonic distance sensors from MaxBotix, with the 0.75 in. NPS WR housing option and additional Parylene coating to prevent corrosion of the aluminum transducer. The distance sensors have a range of $300-5000 \mathrm{~mm}$, a maximum sampling frequency of $6.67 \mathrm{~Hz}$, and a stated resolution of $1 \mathrm{~mm}$ in controlled settings. In this work, we do not correct for the effects of temperature on the sonar measurements, which results in daily mm-scale fluctuations in the sonar records; we discuss options for temperature compensation if greater accuracy is desired in the Future considerations section. The sonars are connected via serial output to a Mayfly Data Logger microprocessor board from EnviroDIY (Ensign et al. 2019). The Mayfly Data Logger is compatible with the Arduino IDE software, and features a microSD memory card socket, six Grove-style sockets for sensor connection, an onboard real-time clock, and solar lithium polymer (lipo) battery charging. We power the Mayfly with a $2500 \mathrm{mAh}$ lipo battery, which is supplemented by a 0.5 watt solar panel $(55 \times 70 \mathrm{~mm})$, and store data on an $8 \mathrm{~GB}$ microSD card. The hardware components are shown in Figure 1a.

The hardware components are housed within a watertight ABS enclosure with a clear, gasket-sealed lid (Figure 1b). The solar panel is placed inside the enclosure up against the inside of the clear lid. To insulate the internal components, we covered the outside of the enclosure (except for the lid) with a layer of reflective aluminum tape, and placed a fitted, opaque sunshield directly behind the solar panel to shade the Mayfly and battery. The output wire from the bed sensor enters the enclosure through a stainless- steel cable gland installed in the sidewall of the enclosure. The water sensor enters the enclosure directly through a hole in the bottom and is secured with a $0.75 \mathrm{in}$. lock nut, a neoprene O-ring (Figure 1c), and silicone caulking around the opening. Before entering the enclosure, the water sonar also passes through a hole drilled in a flat PVC cap (Figure 1d). This allows the entire ensemble to slip onto the end of the well, with the water sensor inside the well and the enclosure resting on top (Figure 2).

We currently use a closed-source camera - the Bushnell Impulse cellular trail camera - to gather video and images for ground truthing the sensor readings. The camera connects via cellular service to a mobile- and web-based application where the user can change settings and view transmitted photos. The camera also stores the images and video locally to an SD card. Users pay a monthly fee for the service based on the amount of data to be transferred, with the cheapest plan starting at \$9.99 USD per month. While any, less expensive trail camera can be mounted to the structure, we chose the Bushnell Impulse so that we can view images from the camera in near-real time, and operate the camera remotely. This re- 

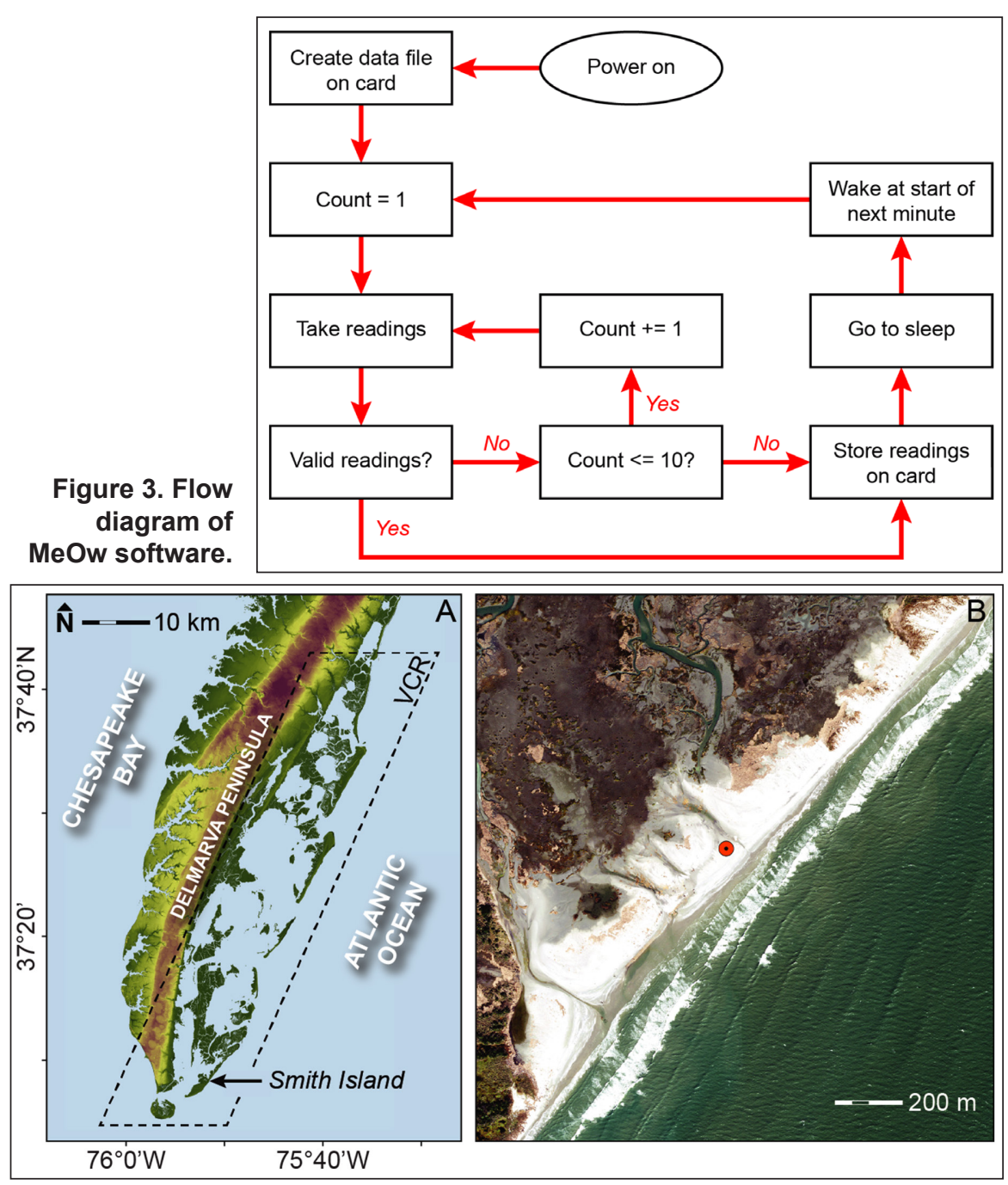

Figure 4. (A) Map of Smith Island within the Virginia Coast Reserve, U.S. MidAtlantic, and (B) aerial imagery from 2018 of the deployment location for our field test experiment, with the MeOw location indicated by the red dot.

mote operation allows us to program the camera to collect images or videos for the duration of discrete events at a frequency that would likely be unsustainable for long (months to years) deployments, considering storage and battery limitations.

\section{Structure}

The well housing the water sensor is made from a PVC pipe (120 in. length, 2 in. diameter) drilled with holes (5/32 in. diameter, spaced every 3 in.), and plugged at the bottom (Figure 2). While purpose-made slotted PVC well screens are ideal for this application - in that they maximize water flow while stopping sand from entering the well - we found that the ultrasonic distance sensors did not work within them, presumably because the horizontal slotting in the well interferes with the sonar system. The subaerial portion of the well is stabilized with a zinc-plated slotted angle iron (96 in. length, $1.5 \mathrm{in}$. width, 14 gauge) secured to the PVC pipe at three locations using stainless steel hose clamps. The bed sensor is positioned at the end of a $26 \mathrm{in}$. aluminum angle arm ( 1 in. wide, 1/16 in. thick), secured to the angle iron at the top of the well casing and with a triangulated brace (Figure 2). We run a PVC pipe (1 in. diameter) along the top of the arm, and attach a standard 0.75 in. threaded PVC pipe fitting on the end at 90 degrees (facing downwards). The bed sonar is screwed into this fitting, and the wire connecting the sensor to the computer board is placed within the PVC for protection. Lastly, we bolt a triangulated camera mount made from aluminum angle ( 1 in. wide, 1/16 in. thick) to the angle iron at the top of the well. The camera attaches to the mount at a 30-degree downward tilt with a standard 1/4-20 camera screw.

\section{Software and processing}

The software used to run the sonars and $\log$ the data is written with the Arduino
IDE. A flowchart of the software that runs on the Mayfly is given in Figure 3, and the process is described as follows. At the start of every minute, the Mayfly board awakens and takes readings from both sensors. If a sensor returns a "bad" reading (i.e. 0 , 300 , or $5,000 \mathrm{~mm}$ ), it will attempt up to nine additional readings until a "good" reading is returned; if 10 consecutive attempts are deemed bad, the bad reading is stored (we later filter these readings out during post-processing, as described in the following paragraph). The readings from both sensors are then logged as a single line (comma-separated) in a text file on the microSD card. In addition to the two distance readings, the board also logs the DateTime, Unix time, on-board temperature, and battery voltage for each sample. Once logging is complete, the Mayfly board goes to sleep to conserve power, waking at the start of the following minute to take the next readings. The code can be modified to sample water and bed elevations at different frequencies, if desired. Optionally, a serial OLED monitor can be connected to the Mayfly board to display sonar readings in real time. We use this functionality during field installation to ensure sensors are working properly, but do not leave the monitor connected for the field experiment.

We process the sonar data using a Python script. The script filters out measurements that fall above or below user-defined thresholds (including those that were recorded as "bad"). For the data presented here, we set the upper threshold to $3,000 \mathrm{~mm}$ (118 in., the approximate length of the well) and the lower threshold to $500 \mathrm{~mm}$, just beyond the blanking distance. The script takes elevations for both sensors as user input, which it uses to convert sonar distances to surface elevations (described in more detail below), and then plots the sensor elevations over time. The code is available online from Reeves (2021).

\section{Field installation tests}

We tested the MeOw stations on Smith Island, VA, a remote, undeveloped barrier island within the Virginia Coast Reserve (VCR). Six MeOws were installed on 21 August 2019 in an alongshore array, and retrieved 93 days later on 22 November 2019. No maintenance visits were performed. Four stations were located on low-lying overwash flats, and the remaining two were installed on coastal dunes. Extensive erosion $(>1 \mathrm{~m})$ compromised 
the two dune-mounted sensors: upon retrieval, one $\mathrm{MeOw}$ was found tilted (yet still functional) and the other fully collapsed on the beach (see the Future considerations section for potential ways to resolve this sort of issue). The four stations on the overwash flat remained functioning and recorded data during the deployment. The following analysis focuses on one of the stations in the low-lying overwash flat (Figure 2) as a demonstration of the results that can be obtained with a $\mathrm{MeOw}$ station. The example $\mathrm{MeOw}$ is located within a narrow section of the island, just landward of the berm at the time of installation (Figure 4). Aerial imagery from 2018 shows evidence of significant overwash and breaching along this section of Smith Island (Figure 4a).

To install each station, we first used a hand auger (3.5 in. diameter) to dig a hole for the well structure approximately 1.5 m deep. We drove rebar (120 in. length, $0.5 \mathrm{in}$. diameter) down the side of the hole to the point of refusal, dropped the well structure into the hole, and fastened the well to the rebar with stainless steel hose clamps to provide additional stability.

During Hurricane Dorian (6 September 2019) and portions of Tropical Storm Melissa (13 October 2019), the camera was programmed to take 60 -second video clips every 15 minutes. We limited camera usage to two photos per day for all other time periods, which we found was overly conservative given that upon retrieval the battery was at approximately $90 \%$ and the camera SD card at only $9 \%$ capacity. We used a Nikon DTM-322 total station to measure the elevation of the sensors on Smith Island. We measured the surface elevation directly below the bed sensor and at the base of the well, and then used a tape measure to record the distance separating the surface from each sensor.
We verified the tape measurements for the bed sensor using the initial sonar readings.

\section{RESULTS}

The bed sensor captured significant changes in water and bed elevations throughout the duration of the experiment, both during high tide events and over the course of three storm events: Hurricane Dorian, Tropical Storm Melissa, and a nor'easter (Figure 5). We explain our interpretation of the raw data (Figure 5b-c) as follows. Examining both sonar sensors in tandem, we can identify periods of no overwash as times when the well sensor measurement is consistently lower than or equal to the bed level sensor measurement - i.e. there is no water above the sediment bed. We identify overwash events in the time series by a cloud of data points from both sensors that follow flat, continuous measurements from the bed sonar; that is, measure-

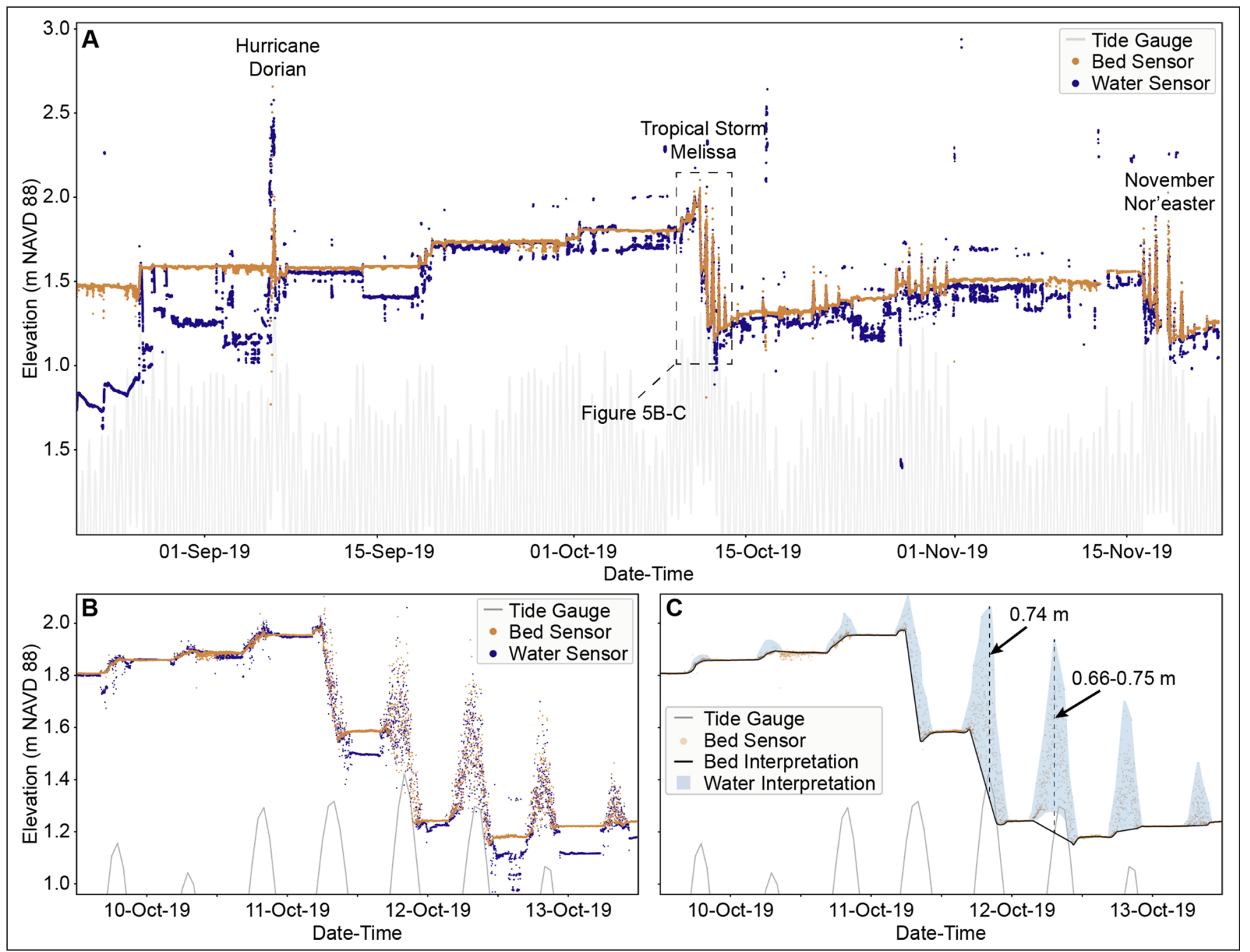

Figure 5. Elevation observations from water (blue) and bed (brown) sensors (A) over the duration of the deployment, and (B) during Tropical Storm Melissa (9-13 October 2019). (C) shows our interpretation of the sonar measurements from $(B)$, with the black line representing the interpreted bed surface, the blue shaded regions representing the range of overwash water elevations, and two events labeled with their maximum estimated depths. 

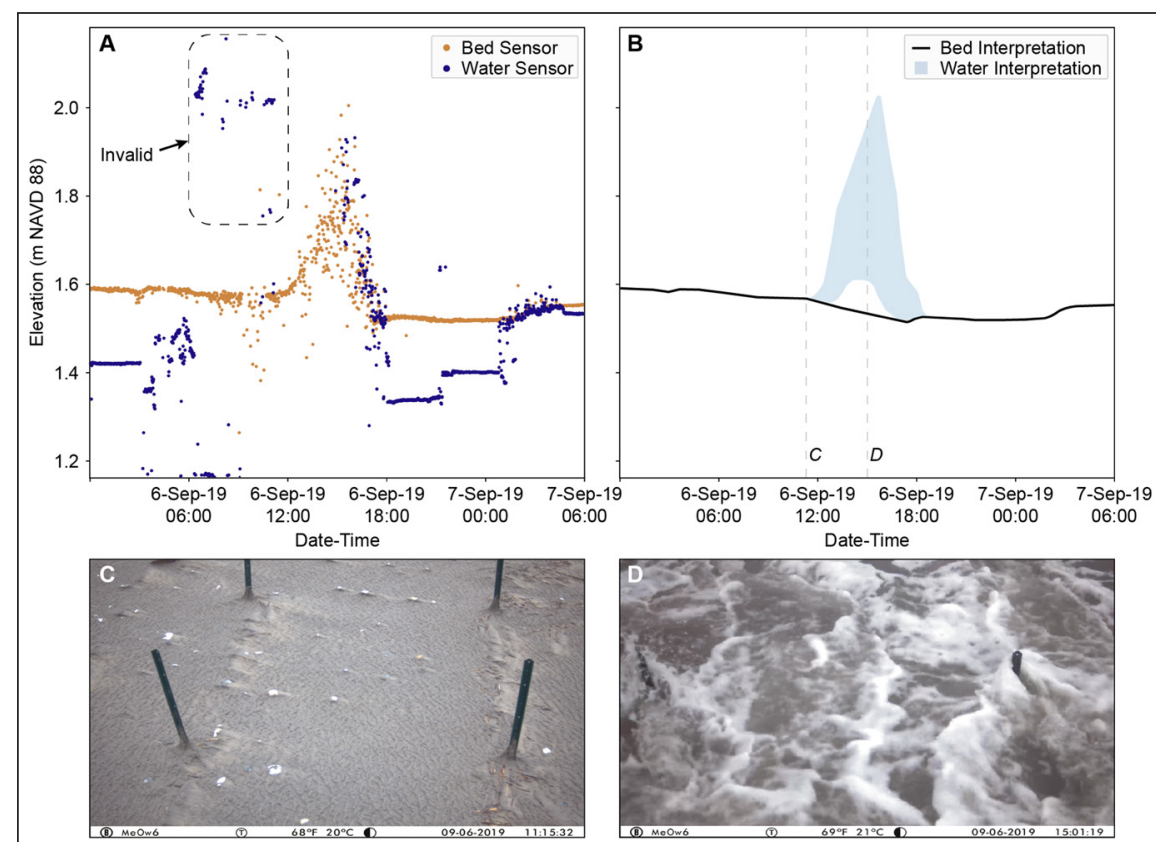

Figure 6. (A) Measurements from the bed and water sensors during Hurricane Dorian, and (B) our interpretation of the raw data from (A). Video stills from the on-board camera on 6 September 2019 at 11:15 (C) and 15:00 (D) EST. The timing of the video captures for (C) and (D) are identified in (B) by vertical dashed lines. The measurements within the dashed box in (A) are determined to be invalid after reviewing video taken during the event (C).

ments from the bed sensor tend to show variance when the reflected surface is overwashing flow, and no variance when the reflected surface is the bed. Timestamped video taken during Hurricane Dorian corroborates this interpretation (Figure 6). Further, during retrieval of the $\mathrm{MeO}$ w station, we observed that the berm had eroded landward such that the $\mathrm{MeOw}$ was now positioned atop the berm crest. This, in conjunction with analysis of the full time series of bed level change (not shown), supports the assumption that all interpretations of water above the sediment bed correspond to berm overtopping and overwashing flows and not uprushing/downrushing run-up events.

Data from the water sensor inside the well was often found to be erroneous when compared to elevations from the bed sensor and camera imagery. For example, during Hurricane Dorian, the water sensor in the well indicated that high water levels occurred in the hours preceding visual verification of overwash from the video (Figure 6), therefore invalidating these results (the measurements from the bed sensor are corroborated by the video, however). We suspect that these invalid readings were caused by the tropical storm force winds vibrating or bending the PVC well (apparent in video taken during the event), thereby causing the sonar signal to reflect off the sides of the well internally and disrupting the sonar reading. It is also likely that erroneous water elevations measured during non-storm conditions within the well can be attributed to interference by the well casing. It should be noted that about 17 days after installation (following Hurricane Dorian), the well had filled with sediment to roughly the elevation of the sediment bed surrounding the well. Upon retrieval, there was no evidence to suggest horizontal or vertical movement of the $\mathrm{MeOw}$ structure, but we cannot confirm that there was no vertical movement of the well structure because the $\mathrm{MeOw}$ station was only geo-referenced relative to the bed elevation at installation.

In the absence of high-frequency image collection (once per minute), we cannot determine what surface (bed or water) each sensor measures for each data point during an overwash event. Therefore, we estimate overwash inundation depth using two methods. First, we calculate the overwash depth as the maximum range between contemporaneous maximum and minimum envelope elevations of an overwash event. However, the minimum envelope elevation could represent an inundated surface, and not the sediment bed. Therefore, we also use a linear model to interpolate a surface between the initial and final bed level during an overwash event and calculate the overwash depth as the difference between the maximum envelope elevation and the contemporaneous elevation of the interpolated bed surface. Hence, for overwash events where the minimum envelope separates from the interpolate line, we provide a range of estimated overwash inundation depths. Figure $5 c$ and Figure $6 \mathrm{~b}$ show our interpretations of the raw data presented in Figure 5b and Figure 6a, respectively, including our estimates of overwash inundation depth.

Based on our interpretation of the raw data, the greatest overwash water depth recorded over the testing period was approximately $0.83 \mathrm{~m}$ on the morning of 18 November 2019 during a nor'easter that impacted the site from 16-19 November. The most dramatic bed level change occurred during 9-13 October 2019 (Tropical Storm Melissa). During this storm, initial accretion of approximately $0.15 \mathrm{~m}$ was followed by $0.77 \mathrm{~m}$ of erosion (Figure $5 \mathrm{~b}$ and $5 \mathrm{c}$ ). Periods of overwash and resulting bed level change coincided with high tides. Water depths reached a maximum of approximately $0.74 \mathrm{~m}$ above the active sediment surface at high tide on the night of 11 October 2019. In contrast, the impacts of Hurricane Dorian were minimal (Figure 6). During this storm event the sediment surface eroded by approximately $0.05 \mathrm{~m}$, and was inundated up to a maximum depth of approximately $0.45 \mathrm{~m}$. The peak overwash depth coincided with the measured high tide. Video collected during Hurricane Dorian corroborates our interpretation of the raw data (Figure 6c-d).

\section{DISCUSSION}

The MeOw stations successfully capture high frequency $(1 / 60 \mathrm{~Hz}), \mathrm{cm}$-scale water and sediment surface elevations over long deployment durations. The field test presented here lasted 93 days, with the battery powering the Mayfly and sonars remaining at near full charge throughout the experiment and the 8 GB microSD card at $<<1 \%$ capacity upon removal. Additionally, the station withstood tropical storm force winds, rain, wave action, and decimeter-scale erosion and accretion over the duration of our field testing. Hence, the $\mathrm{MeOw}$ stations are ideally suited for measuring storm overwash - or any process that necessitates tracking bed and water level elevations at high frequency dur- 
ing harsh conditions. Notably, while the deployment described here lasted only three months, $\mathrm{MeOw}$ sonars deployed elsewhere have continued to remain operational sampling at $1 / 60 \mathrm{~Hz}$ for over 535 days unattended. Depending on the type and frequency of use, the camera may need more frequent maintenance than the sonar sensors. However, for the three-month experiment on Smith Island with a conservative sampling frequency, the camera battery was at approximately $90 \%$ at the end of the experiment. The longevity of the $\mathrm{MeOw}$ system is beneficial for long-term analyses and remote deployments where frequent access is limited.

Our results demonstrate the ability of high-frequency bed-level measurements in constraining estimates of overwash inundation depth. The $\mathrm{MeO}$ wed sonar measures the sediment surface elevation immediately before and after each overwash event. Although our interpretation of the raw data sometimes requires interpolation of the bed level between these two times (i.e. over the course of an event), the period of time we interpolate is only hours rather than weeks compared to other, more infrequent bed level measurement techniques (e.g. Sherwood et al. 2014; VanDusen et al. 2016). Therefore, we can make robust estimates of overwash inundation depths given high confidence in bed levels.

\section{Limitations}

The water sensor inside the well performed poorly relative to the bed sensor, presumably because the sonar signal was frequently disrupted by the perforations in the well and/or the well vibrating and flexing in strong winds. We found that the sonar readings inside the well were especially poor during very high wind events (Hurricane Dorian in particular). Additionally, the well quickly filled with sediment, canceling its ability to measure groundwater levels during times in between active overwash, such as observed in VanDusen et al. (2016). Contemporaneous water level measurements using a secondary method would improve confidence in the sonar measurements, but were not within the scope of this project. As such, the measurements from the water sensor serve principally as corroboration for the bed sonar measurements preand post-storm. As in VanDusen et al. (2016), frequent video and/or photos are important for validating measurements and investigating inconsistencies. Based on these shortcomings, other methods may work better than the ultrasonic distance sensor for measuring water levels inside the well.

Our sensors measure at a frequency of $1 / 60 \mathrm{~Hz}$. While this frequency consumes little energy and is sufficient for measuring mean water level and bed elevations, higher frequencies $(>2 \mathrm{~Hz})$ are needed to capture wave processes, individual runup events, and therefore potentially differentiate between run-up and inundation overwash with higher confidence. While $\mathrm{MeOw}$ storage capacity is sufficient for higher sampling frequencies, the potential battery life for higher sampling rates is unknown. For long deployments (months to years) measuring at such frequencies, the $\mathrm{MeOw}$ would likely require a larger battery source and solar array in order to maintain a similar longevity.

\section{Future considerations}

There is potential for future work to refine the $\mathrm{MeO}$ w instrument suite. First, the camera is currently a proprietary system, and future work could include replacing this system with a lower cost and open source system (i.e. a Raspberry Pi camera) that could likewise transmit images in real time. Second, the station itself could also serve as a host to other instruments, including tools to measure sediment concentration in overwashing flows (e.g. Eidam et al. 2020), meteorological sensors (air temperature and pressure), and open-source pressure transducers for measurement of groundwater dynamics (Temple et al. 2020). Third, the station camera took 60-second video clips every 15 minutes during the three storm events. Frequent image data can confirm if a sonar measurement is recording the elevation of the bed, or the water above the bed. We can envision a system that records more images and uses automated methods (i.e. machine learning) to analyze these images to determine the actual reflected surface (e.g. water or sand). Fourth, the station can incorporate other new types of water level sensors, both in and outside the well (e.g. eTape; https:// milonetech.com). Fifth, all sensor data could be transmitted in real-time using LoRa (Long Range radio bands), cellular service, deploying in a location with $\mathrm{WiFi}$, or through a combination of radio and cellular technology using a wireless mesh network.
We did not correct for the effect of temperature on the sonar measurements, the lack of which led to daily $\mathrm{mm}$-scale fluctuations in the sonar records. If greater accuracy is desired, the data can either be post-processed using observations from a nearby meteorological station, or an external temperature sensor (Maxbotix HR-MaxTemp) can be hardwired directly to each sensor for real-time temperature compensation. Additionally, to prevent sediment infiltration into the well, the well casing could be vented with smaller or more infrequent holes or wrapped externally with a filter screen.

The stability of the station depends on its burial depth. The burial depth would be of particular concern in areas where a high water table inhibits the depth of the hole (if hand augering), or where considerable erosion (e.g. $>1.5 \mathrm{~m}$ ) is possible, such as on a dune system prone to scarping and erosion (as in this study). As such, future deployments could incorporate jet pumps or other post-driving techniques to advance the well to greater depths. In addition, if additional stabilization is needed, the PVC well casing could be secured to a vertical tripod or goal-post structure.

\section{CONCLUSIONS}

The MeOw (Measuring Overwash) stations are durable, low-cost, and can capture high-frequency, $\mathrm{cm}$-scale water and sediment surface elevations associated with overwash over the course of several months to years. The $\mathrm{MeOw}$ stations consist of one ultrasonic distance sensor inside a stilling well to measure water levels, and another attached to an arm extending outwards from the well to measure the elevation of the sediment surface (when dry) or the water surface (when inundated). The sensors are controlled by an open-source microprocessor board, and the stations feature a wireless trail camera attached to the well structure to provide images and video to corroborate the sonar measurements. We tested our $\mathrm{MeOw}$ station in fall 2019 on a frequently overwashed area of Smith Island, VA, for 93 days. The $\mathrm{MeO}$ w station had (effectively) full battery power and storage space upon conclusion of the experiment, and had survived through several strong storms, including Hurricane Dorian. The $\mathrm{MeOw}$ station observed significant variability in bed level over the course of the experiment, demonstrating the importance of high-frequency bed elevation 
measurements for accurate estimates of overwash inundation depths. While the sonar mounted externally on the arm performed competently, the sonar mounted within the well casing was noisy; thus, we suggest using an alternative water-level sensor (e.g. pressure transducer, eTape) to improve upon our methodology.

\section{ACKNOWLEDGMENTS}

This work is supported by the Virginia Coast Reserve Long-Term Ecological Research Program (National Science Foundation DEB-1832221) and the Preston Jones and Mary Elizabeth Frances Dean Martin Fellowship Fund from the Department of Geological Sciences at the University of North Carolina at Chapel Hill. The data for the results presented in this manuscript are available online alongside processing/plotting code (Reeves 2021), and data from additional $\mathrm{MeOw}$ stations not presented herein are published in repository (Reeves et al. 2021). We thank Michael Itzkin and Elsemarie Mullins for assistance in the field, and Cora Baird, Jonah Morreale, and David Lee for logistical support.

\section{REFERENCES}

Anarde, K., Figlus, J., Sous, D., and M. Tissier, 2020. "Transformation of infragravity waves during hurricane overwash." J. Marine Science and Engineering, 8(8), 545.

Baldock, T.E., Weir, F. and M.G. Hughes, 2008. "Morphodynamic evolution of a coastal lagoon entrance during swash overwash." Geomorphology, 95, 398-411.

Borrell, S.J., and J.A. Puleo, 2019. "In situ hydrodynamic and morphodynamic measurements during extreme storm events." Shore \& Beach, 87(4), 23-30.

Bray, T.F., and C.H. Carter, 1992. "Physical processes and sedimentary record of a modern, transgressive, lacustrine barrier island." Marine Geology, 105, 155-168.

Cohn, N., Hoonhout, B.M., Goldstein, E.B., De Vries, S., Moore, L.J., Durán Vinent, O., and P. Ruggiero, 2019. "Exploring marine and aeolian controls on coastal foredune growth using a coupled numerical model." J. Marine Science and Engineering, 7(1), 13.

Coogan, J.S., Webb, B.M., Smallegan, S.M., and J.A. Puleo, 2019. "Geomorphic changes measured on Dauphin Island, AL, during Hurricane Nate." Shore \& Beach, 87(4), 15.

Cressey, D., 2017. "The DIY electronics transforming research.” Nature News, 544(7648), 125.

Dolan, R., and P. Godfrey, 1973. "Effects of Hurricane Ginger on the barrier islands of North Carolina." Geological Society of America Bulletin, 84(4), 1329-1334.
Donnelly, C., Kraus, N., and M. Larson, 2006. "State of knowledge on measurement and modeling of coastal overwash." J. Coastal Research, 22(4), 965-991.

Eidam, E., Langhorst, T., Richardson, C., and E.B. Goldstein, 2020. "Economical DIY optical backscatter sensors for measurements of turbidity and sediment concentrations." $A G U$ 2020 Fall meeting, 1-17 December 2020.

Engelstad, A., Ruessink, B.G., Wesselman, D., Hoekstra, P., Oost, A., and M. van der Vegt, 2017. "Observations of waves and currents during barrier island inundation." J. Geophysical Research: Oceans, 122(4), 3152-3169.

Ensign, S., Arscott, D., Hicks, S., Aufdenkampe, A., Muenz, T., Jackson, J., and D. Bressler, 2019. “A digital Mayfly swarm is emerging." Eos, 100.

Fisher, J.S., Leatherman, S.P., and F.C. Perry, 1975. "Overwash processes on Assateague Island." In Coastal Engineering 1974, ASCE, Copenhagen, Denmark, 1194-1212.

Hoekstra, P., Haaf, M.T., Buijs, P., Oost, A., Breteler, R.K., van der Giessen, K., and M. van der Vegt, 2009. "Washover development on mixedenergy, mesotidal barrier island systems." In Proc. Coastal Dynamics 2009, World Scientific, Tokyo, Japan, 1-12.

Holland, K.T., Holman, R.A., and A.H. Sallenger, 1991. "Estimation of overwash bore velocities using video techniques." In Coastal Sediments '91, ASCE, Seattle, WA, 489-497.

Houser, C., 2012. "High-frequency bed elevation measurements using ultrasonic distance sensors." Aeolian Research, 6, 75-81.

Larson, M., Wise, R.A., and N.C. Kraus, 2004. "Coastal Overwash: Part 2, Upgrade to SBEACH." Technical Report ERDC/RSMTN-15, U.S. Army Engineer Research and Development Center, Vicksburg, MS.

Lashley, C.H., Bertin, X., Roelvink, D., and G. Arnaud, 2019. "Contribution of infragravity waves to run-up and overwash in the Pertuis Breton embayment (France)." J. Marine Science and Engineering, 7(7), 205.

Lazarus, E.D., Goldstein, E.B., Taylor, L.A., and H.E. Williams, 2021. "Comparing patterns of hurricane washover into built and unbuilt environments." Earth's Future, e2020EF001818.

Leatherman, S.P., and R.E. Zaremba, 1987. "Overwash and aeolian processes on a US Northeast coast barrier." Sedimentary Geology, 52, 183-206.

Lorenzo-Trueba, J., and A. Ashton, 2014. "Rollover, drowning, and discontinuous retreat: Distinct modes of barrier response to sea-level rise arising from a simple morphodynamic model." J. Geophysical Research: Earth Surface, $119,779-801$.

Matias, A., Ferreira, Ó., Vila-Concejo, A., Morris, B., and J.A. Dias, 2010 "Short-term morphodynamics of non-storm overwash." Marine Geology, 274, 69-84.

Matias, A., and G. Masselink, 2017. "Overwash Processes: Lessons from Fieldwork and Laboratory Experiments." In Coastal Storms, John Wiley \& Sons, Hoboken, NJ, 175-194.

Matias, A., Carrasco, A.R., Loureiro, C., Masse- link, G., Andriolo, U., McCall, R., Ferreira, Ó., Plomaritis, T.A., Pacheco, A., and M. Guerreiro, 2019. "Field measurements and hydrodynamic modelling to evaluate the importance of factors controlling overwash." Coastal Engineering, 152, 103523.

Moore, L.J., List, J.H., Williams, S.J., and D. Stolper, 2010. "Complexities in barrier island response to sea level rise: Insights from numerical model experiments, North Carolina Outer Banks." J. Geophysical Research, 115, F03004.

Nelson, S.A., and S.F. Leclair, 2006. "Katrina’s unique splay deposits in a New Orleans neighbourhood." GSA Today, 16, 4-10.

Nordstrom, K.F., 1994. "Beaches and dunes of human-altered coasts." Progress in Physical Geography, 18(4), 497-516.

Pearce, J.M., 2012. "Building research equipment with free, open-source hardware." Science, 337(6100), 1303-1304.

Reeves, I., Goldstein, E., Anarde, K., and L. Moore, 2019. "High-frequency observations of overwash water and bed elevations from five $\mathrm{MeOw}$ (Measuring Overwash) stations: Smith Island, VA, August-November 2019." Virginia Coast Reserve Long-Term Ecological Research Project Data Publication knb-ltervcr.324.2, https://doi.org/10.6073/pasta/9d8 66b9636973697984ae92a688d0f4b.

Reeves, I., 2021. "MeOw Software and Instructions." Zenodo, Version v1.0, http://doi.org/10.5281/ zenodo.4540900

Rogers, L.J., Moore, L.J., Goldstein, E.B., Hein, C.J., Lorenzo-Trueba, J. and A.D. Ashton, 2015. "Anthropogenic controls on overwash deposition: Evidence and consequences." J. Geophysical Research: Earth Surface, 120, 2609-2624.

Roelvink, D., Reniers, A., Van Dongeren, A.P., De Vries, J.V.T., McCall, R., and J. Lescinski, 2009. "Modelling storm impacts on beaches, dunes and barrier islands." Coastal Engineering, 56(11-12), 1133-1152.

Sallenger, A.H., 2000. "Storm impact scale for barrier islands." J. Coastal Research, 16, 890-895.

Sherwood, C.R., Long, J.W., Dickhudt, P.J., Dalyander, P.S., Thompson, D.M., and N.G. Plant, 2014. "Inundation of a barrier island (Chandeleur Islands, Louisiana, USA) during a hurricane: Observed water-level gradients and modeled seaward sand transport." J. Geophysical Research: Earth Surface, 119, 1498-1515.

Temple, N.A., Webb, B.M., Sparks, E.L. and A.C. Linhoss, 2020. "Low-Cost Pressure Gauges for Measuring Water Waves." J. Coastal Research, 36(3), 661-667.

VanDusen, B.M., Theuerkauf, E.J., Fegley, S.R., and A.B. Rodriguez, 2016. "Monitoring overwash using water-level loggers resolves frequent inundation and run-up events." Geomorphology, 254, 32-40.

Walters, D., Moore, L.J., Durán Vinent, O., Fagherazzi, S., and G. Mariotti, 2014. "Interactions between barrier islands and backbarrier marshes affect island system response to sea level rise: Insights from a coupled model." J. Geophysical Research: Earth Surface, 119, 2013-2031. 